Research Paper

\title{
Immunological cytokine profiling identifies TNF- $\alpha$ as a key molecule dysregulated in autistic children
}

\author{
Jiang Xie ${ }^{1,2}$, Li Huang ${ }^{1,2}$, Xiaohong Li $^{3}$, Hua Li ${ }^{1}$, Yongmei Zhou ${ }^{1}$, Hua Zhu ${ }^{1}$, Tianying \\ Pan $^{4}$, Keith M. Kendrick ${ }^{5}$ and Wenming $X_{u^{4,6}}$ \\ ${ }^{1}$ The Third People's Hospital of Chengdu, Affiliated Hospital of Southwest Jiao Tong University Medical School, Chengdu, China \\ ${ }^{2}$ Department of Clinical Medicine, Southwest Medical University, Luzhou, China \\ ${ }^{3}$ National Office for Maternal and Child Health Surveillance of China, Department of Obstetrics, West China Second University \\ Hospital, Key Laboratory of Birth Defects and Related Diseases of Women and Children, Ministry of Education, Sichuan \\ University, Chengdu, China \\ ${ }^{4}$ Department of Obstetrics and Gynecology, West China Second University Hospital, Key Laboratory of Birth Defects and \\ Related Diseases of Women and Children, Ministry of Education, Sichuan University, Chengdu, China \\ ${ }^{5}$ Key Laboratory for Neuroinformation, Center for Information in Medicine, University of Electronic Science and Technology \\ of China, Chengdu, China \\ ${ }^{6}$ Joint Laboratory of Reproductive Medicine, SCU-CUHK, West China Second University Hospital, Sichuan University, Chengdu, \\ China \\ Correspondence to: Wenming Xu, email: Xuwenming1973@163.com \\ Keith M. Kendrick, email: kkendrick@uestc.edu.cn \\ Keywords: TNF- $\alpha$, cytokines, autism, THRIL MRNA, LinCRNA \\ Abbreviations: ASD: autism spectrum disorder; ABC: Autism Behavior Checklist \\ Received: April 25, $2017 \quad$ Accepted: June 11, $2017 \quad$ Published: July 18, 2017 \\ Copyright: Xie et al. This is an open-access article distributed under the terms of the Creative Commons Attribution License 3.0 \\ (CC BY 3.0), which permits unrestricted use, distribution, and reproduction in any medium, provided the original author and source \\ are credited.
}

\section{ABSTRACT}

Recent studies have suggested that the etiology of autism spectrum disorder (ASD) may be caused by immunological factors, particularly abnormalities in the innate immune system. However, it is still unclear which specific cytokines may be of most importance. The current study therefore investigated which cytokines showed altered concentrations in blood in ASD compared with healthy control children and which were also correlated with symptom severity. Our study sample included 32 children diagnosed with ASD and 28 age and sex-matched typically developing children. Autism symptoms were measured using the Autistic Behavior Checklist $(A B C)$ and blood samples were taken from all subjects. We used Milliplex cytokine kits to determine serum concentrations of 11 Th1, Th2 and Th17 related cytokines. Additionally, expression of THRIL (TNF $\alpha$ and hnRNPL related immunoregulatory LincRNA), a long non-coding RNA involved in the regulation of tumor necrosis factor$\alpha$ (TNF- $\alpha$ ), was determined using real-time PCR. Of the 11 cytokines measured only concentrations of TNF- $\alpha(p=0.002)$, IL-1 $\beta(p=0.02)$ and IL-17a $(p=0.049)$ were significantly increased in ASD children compared to typically developing controls, but only TNF- $\alpha$ concentrations were positively correlated with severity of ASD symptoms on all 5 different ABC sub-scales and were predictive of an ASD phenotype (area under the curve $=0.74$ ). Furthermore, THRIL RNA expression was significantly decreased in ASD children. Our results provide further support for altered innate immunity being an important autism pathogenic factor, with autistic children showing increased blood TNF- $\alpha$ concentrations associated with symptom severity, and decreased expression of the THRIL gene involved in regulating TNF- $\alpha$. 


\section{INTRODUCTION}

Autism spectrum disorder (ASD) is a neurodevelopmental disorder with reports of increasing prevalence during the last decades [1-3] and estimated to affect around $1 \%$ of individuals, equating to over 50 million worldwide [4]. While autistic symptoms are variable the three core characteristics presented are problems with social interactions, language communication and repetitive behavior, with other common features being depression, anxiety and lack of attention [5-7]. It has now been widely accepted that the major pathogenesis of ASD includes contributions from both genetic and environmental factors, with epidemiological results from twin studies showing that at least $60 \%$ percent of etiology can be linked to gene alterations [8], although it seems likely that multiple genes are involved. There has therefore been an increasing emphasis on identifying potential biochemical markers which may assist in early diagnosis of the disorder in order to allow early therapeutic intervention.

Recent studies have provided increasing evidence that immunological factors, particularly pro-inflammatory ones, may play an important role in the etiology of autism [9-12] and indicate that abnormalities in the innate immune system could be a predominant feature of ASD. Cytokines as a broad category of small proteins secreted from immune cells like macrophages and $\mathrm{T}$ lymphocytes are critical mediators of the immune response. $T$ cells include several subtypes, such as Th1, Th2 and Th17 and a number of studies have reported altered concentrations of a range of different cytokines in blood samples from ASD patients [13-15]. In terms of their potential use as an early biomarker for ASD recent studies have also reported cytokine changes can be detected in both amniotic fluid $[16,17]$ and neonatal blood [18] samples. Currently, increased concentrations of interleukins (IL - IL-1 $\beta$, IL4 , IL-6) and tumor necrosis factor- $\alpha$ (TNF $\alpha$ ) have also commonly been reported in ASD [13-15, 19-23], although it is still unclear which cytokines are the most reliable biomarkers and which are also associated with symptom severity. It is therefore important to establish in more detail which of the many different candidate cytokines related to innate immunity and Th1, Th2 or Th17 show the most consistent alterations in blood concentrations in ASD children and are also associated with symptom severity. In addition, it is important to establish whether altered concentrations of specific candidate cytokines related to ASD are associated with corresponding changes in the expression of genes involved in their regulation.

In the current study, we have measured blood concentrations of 11 different Th1,2 and 17 cytokines in a sample of ASD children and typically developing children from the southwest of China. The study particularly identified TNF- $\alpha$ as showing altered concentrations in
ASD children which were associated with symptom severity and so in an additional preliminary analysis we also measured altered expression of the recently cloned long noncoding RNA, THRIL (TNF $\alpha$ and hnRNPL-related immunoregulatory large intergenic non-coding RNA (lincRNA)), which is involved in the regulation of TNF- $\alpha$ via heterogeneous nuclear ribonucleoprotein L (hnRNPL) [24].

\section{RESULTS}

\section{Demographic comparisons}

While the mean age of the participants did not differ significantly between the autism group and the TD group (t-test, $\mathrm{t}=1.979, \mathrm{p}=0.053$ ), the TD group children tended to be slightly older the ASD children (see Table 1). However, none of the blood cytokine concentrations showed any relationship with age. There were no significant differences in gender composition of the two groups ( $\mathrm{p}=0.192$ ).

\section{Autism symptom (ABC) scores}

All the children in the ASD and TD groups were assessed using the $\mathrm{ABC}$. Total scores for the two groups together with those in each of the ABC's five dimensions are shown in the Table 2, with the ASD group scoring significantly higher than the TD group across all five dimensions and the total score ( $p<0.001$ in all cases).

\section{Cytokine concentrations in the serum of ASD and TD children}

Concentrations of each of the cytokines measured were compared statistically between the ASD and TD groups using t-tests. Table 3 shows serum concentrations of the 11 cytokines we screened in ASD and TD children. TNF- $\alpha(p=0.002), I L-1 \beta(p=0.023)$ and IL-17 $\alpha(p=0.048)$ were significantly increased in the ASD group, although only changes in TNF- $\alpha$ survived correction for multiple testing (Bonferroni adjusted $\mathrm{p}=<0.0045$ i.e. $0.05 / 11$ ). When we performed a receiver operating characteristics (ROC) analysis on the study sample for TNF- $\alpha$, this revealed a good discrimination sensitivity between ASD and TD subjects (area under the curve $=0.7411 \pm 0.065$, $\mathrm{p}<0.01-$ see Figure 1A).

\section{Relationship between cytokine concentrations and $\mathrm{ABC}$ scores}

Spearman correlation analysis showed that of the 3 cytokines exhibiting significant differences between the ASD and TD groups only TNF- $\alpha$ concentrations were positively correlated with all five subscales of the 
Table 1: Sociodemographic characteristics in the study groups

\begin{tabular}{lcccc}
\hline & ASD N=32 & TD N=28 & Value & P \\
\hline Mean Age, years & & & & $>0.05$ \\
Children & $5.51 \pm 1.280$ & $6.11 \pm 1.040$ & 0.830 & 0.410 \\
Birth Weight (g) & $3140.63 \pm 548.670$ & $3012.50 \pm 646.733$ & & 0.192 \\
Sex, N (\%) & & & 1.702 \\
Male & $29(90.63 \%)$ & $22(78.57 \%)$ & & \\
Female & $3(9.38 \%)$ & $6(21.43 \%)$ & \\
\hline
\end{tabular}

Table 2: Autism Behavior Checklist (ABC) total and subscale scores in ASD and TD groups

\begin{tabular}{|c|c|c|c|c|c|c|}
\hline & \multicolumn{2}{|c|}{ ASD $\mathbf{N}=32$} & \multicolumn{2}{|c|}{ TD $\mathbf{N}=\mathbf{2 8}$} & \multirow{2}{*}{ Value } & \multirow{2}{*}{$\mathbf{P}$} \\
\hline & Mean & SD & Mean & SD & & \\
\hline $\begin{array}{l}\text { Sensory } \\
\text { behavior }\end{array}$ & 12.41 & 4.211 & 0.46 & 1.427 & 14.292 & $<0.001$ \\
\hline Social Relating & 19.94 & 6.657 & 1.43 & 3.271 & 13.359 & $<0.001$ \\
\hline $\begin{array}{l}\text { Body and object } \\
\text { use }\end{array}$ & 16.16 & 7.692 & 5.11 & 6.713 & 5.887 & $<0.001$ \\
\hline Language & 15.75 & 6.011 & 1.71 & 3.004 & 11.186 & $<0.001$ \\
\hline $\begin{array}{l}\text { Social and } \\
\text { adaptive }\end{array}$ & 14.25 & 4.711 & 3.21 & 4.14 & 9.574 & $<0.001$ \\
\hline Total score & 78.5 & 15.417 & 11.89 & 14.39 & 17.22 & $<0.001$ \\
\hline
\end{tabular}

Table 3: Blood cytokine concentrations in the ASD and TD groups

\begin{tabular}{|c|c|c|c|c|c|c|}
\hline & \multicolumn{2}{|c|}{ ASD $\mathbf{N}=32$} & \multicolumn{2}{|c|}{ TD $\mathbf{N}=\mathbf{2 8}$} & \multirow{2}{*}{ Value } & \multirow{2}{*}{$\mathbf{P}$} \\
\hline & Mean & SD & Mean & SD & & \\
\hline IL-17F ng/ml & 0.11 & 0.602 & 0.02 & 0.033 & 0.848 & 0.400 \\
\hline IFN- $\gamma \mathrm{pg} / \mathrm{ml}$ & 7.81 & 6.010 & 6.85 & 3.484 & 0.742 & 0.461 \\
\hline IL-10 pg/ml & 0.68 & 0.965 & 0.51 & 0.969 & 0.686 & 0.496 \\
\hline IL-17A pg/ml & 6.92 & 2.982 & 5.65 & 1.761 & 1.963 & $0.048^{*}$ \\
\hline $\mathrm{IL}-22 \mathrm{ng} / \mathrm{ml}$ & 1.30 & 7.245 & 0.24 & 0.625 & 0.771 & 0.444 \\
\hline IL-1B pg/ml & 3.09 & 1.177 & 2.53 & 0.608 & 2.252 & $0.023 *$ \\
\hline IL-2 pg/ml & 3.98 & 1.832 & 3.30 & 1.132 & 1.696 & 0.095 \\
\hline IL-21 pg/ml & 13.34 & 8.717 & 9.76 & 6.390 & 1.792 & 0.078 \\
\hline IL-4 ng/ml & 0.04 & 0.026 & 0.03 & 0.023 & 0.559 & 0.578 \\
\hline IL-6 pg/ml & 3.78 & 5.099 & 1.90 & 2.694 & 1.749 & 0.086 \\
\hline TNF- $\alpha \mathrm{pg} / \mathrm{ml}$ & 12.15 & 4.627 & 8.77 & 3.168 & 3.259 & $0.002 *$ \\
\hline
\end{tabular}

$* \mathrm{P}<0.05$ between the ASD and control groups. 
$\mathrm{ABC}(\mathrm{rs}=0.29-0.41$, all $\mathrm{ps}<0.025)$ as well as the total scores $(r=0.394, p=0.002)$ in the whole study sample (see Table 4). The regression plot in Figure 1B shows a linear correlation across the total ABC scores in the TD and ASD subjects.

To further determine whether TNF- $\alpha$ could be used as an independent predictor of autistic behavior symptoms, a stepwise multiple linear regression model was used. The result shows that only TNF- $\alpha$ was an independent predictor of the total score and all 5 subscales of the ABC (see Tables 4-5).

\section{The expression of long noncoding THRIL mRNA in ASD and TD children}

THRIL is a recently identified long noncoding RNA which could negatively regulate TNF- $\alpha$ expression in THP1 macrophages. Therefore the THRIL-TNF- $\alpha$ regulatory pathway could be altered in ASD patients. As a result of our TNF- $\alpha$ findings we therefore additionally decided to investigate a possible association with THRIL expression. The results showed that THRIL expression was also significantly (t-test, $\mathrm{p}<0.01$ ) decreased in the ASD compared to TD children (Figure 2, $n=10$ for ASD group and $n=8$ for TD subjects).

\section{DISCUSSION}

Our study has provided further support for the potential use of immunological measures as ASD biomarkers with blood concentrations of TNF- $\alpha$ and expression of its associated long noncoding RNA, THRIL, offering the most promising candidates, although IL- $1 \beta$ may also be of importance. Critically, TNF- $\alpha$

A

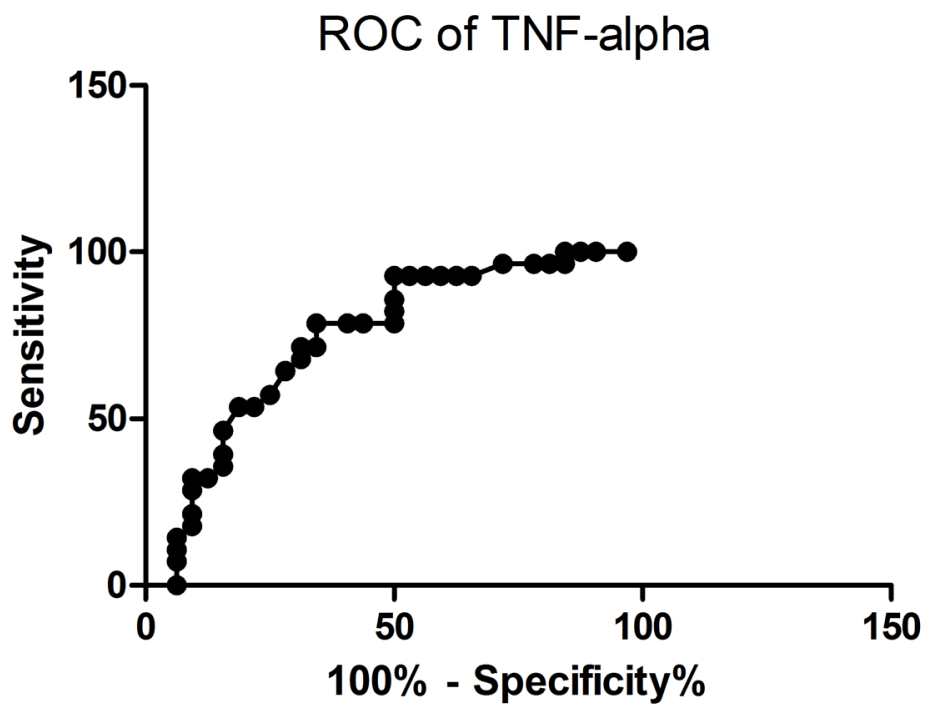

B

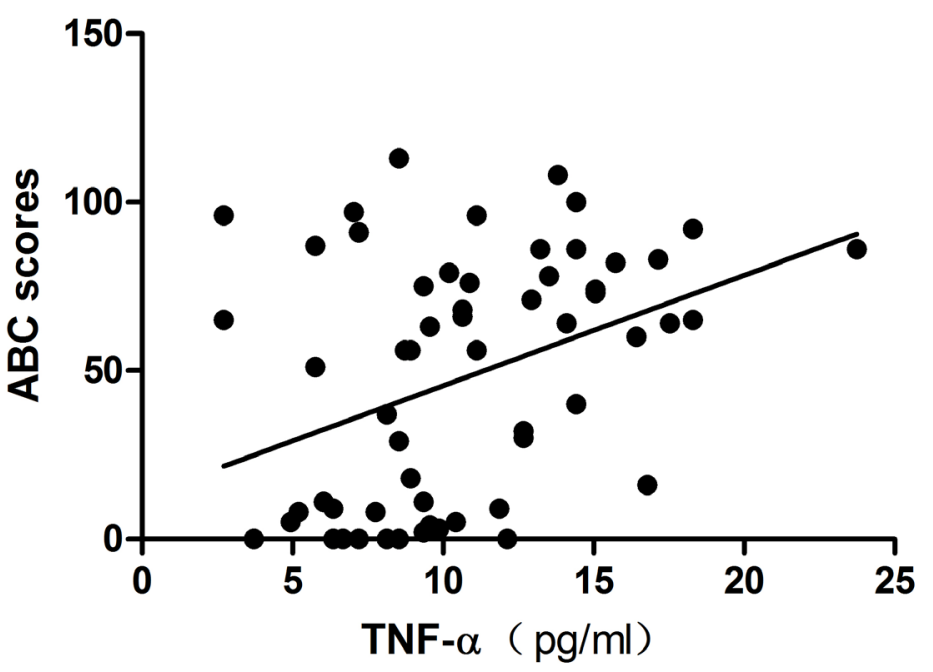

Figure 1: (A) Area under the curve (AUC) plot for prediction sensitivity of blood TNF- $\alpha$ concentrations (pg/ml) and ASD vs TD classification ( $\mathrm{AUC}=0.7411 ; \mathrm{p}<0.01)$. (B) Regression plot showing significant a positive correlation between TNF- $\alpha$ concentrations (pg/ $\mathrm{ml})$ and total Autism Behavior Checklist (ABC) scores ( $\mathrm{r}=0.39 ; \mathrm{p}=0.002)$. 
Table 4: Correlation analysis of cytokine levels and Autism Behavior Checklist (ABC) scores for children in both groups

\begin{tabular}{|c|c|c|c|c|c|c|c|c|c|c|c|c|c|}
\hline & \multirow[t]{2}{*}{$\mathbf{n}$} & \multicolumn{2}{|c|}{ Sensory behavior } & \multicolumn{2}{|c|}{$\begin{array}{c}\text { Social } \\
\text { relating }\end{array}$} & \multicolumn{2}{|c|}{$\begin{array}{l}\text { Body and } \\
\text { object use }\end{array}$} & \multicolumn{2}{|c|}{$\begin{array}{l}\text { Language and } \\
\text { communication }\end{array}$} & \multicolumn{2}{|c|}{$\begin{array}{c}\text { Social and } \\
\text { adaptive skills }\end{array}$} & \multicolumn{2}{|c|}{ Total score } \\
\hline & & $\mathbf{r}$ & $\mathbf{p}^{\mathrm{c}}$ & $\mathbf{r}$ & $\mathbf{p}^{\mathrm{c}}$ & $\mathbf{r}$ & $\mathbf{p}^{\mathrm{c}}$ & $\mathbf{r}$ & $\mathbf{p}^{\mathrm{c}}$ & $\mathbf{r}$ & $\mathbf{p}^{\mathbf{c}}$ & $\mathbf{r}$ & $\mathbf{p}^{\mathrm{c}}$ \\
\hline TNF- $\alpha$ & 60 & 0.290 & $0.025^{*}$ & 0.315 & $0.014 *$ & 0.412 & $0.001 * *$ & 0.388 & $0.002 * *$ & 0.400 & $0.002 * *$ & 0.394 & $0.002 * *$ \\
\hline IL-1 $\beta$ & 60 & 0.235 & 0.071 & 0.159 & 0.224 & 0.251 & 0.054 & 0.258 & $0.046^{*}$ & 0.132 & 0.313 & 0.223 & 0.087 \\
\hline $\begin{array}{l}\text { IL- } \\
17 \mathrm{~A}\end{array}$ & 60 & 0.175 & 0.180 & 0.133 & 0.313 & 0.240 & 0.065 & 0.224 & 0.085 & 0.142 & 0.281 & 0.184 & 0.158 \\
\hline
\end{tabular}

$* \mathrm{P}<0.05)$ between the ASD and control groups.

$* * \mathrm{P}<0.01$ ) between the ASD and control groups.

Table 5: Relationship between cytokines and Autism Behavior Checklist (ABC) scores

\begin{tabular}{|c|c|c|c|c|c|c|}
\hline & \multicolumn{2}{|c|}{$\begin{array}{l}\text { Unstandardized } \\
\text { coefficients }\end{array}$} & \multirow{2}{*}{$\begin{array}{c}\text { Standardized } \\
\text { coefficients }\end{array}$} & \multirow{2}{*}{$\mathbf{T}$} & \multirow[t]{2}{*}{$\mathbf{P}$} & \multirow{2}{*}{$\begin{array}{c}\text { Model } \\
\text { adjusted } R^{2}\end{array}$} \\
\hline & B & SE & & & & \\
\hline \multicolumn{7}{|c|}{ Model 1. Sensory behavior score as dependent variable } \\
\hline 1. Constant & -2.144 & 3.114 & & -0.689 & 0.494 & 0.106 \\
\hline 2. Gender & 4.690 & 2.339 & 0.248 & 2.005 & 0.050 & \\
\hline 3. TNF- $\alpha$ & 0.472 & 0.195 & 0.300 & 2.427 & 0.018 & \\
\hline \multicolumn{7}{|c|}{ Model 2.Social relating score as dependent variable } \\
\hline 1. Constant & -2.966 & 4.898 & & -0.606 & 0.547 & 0.108 \\
\hline 2. Gender & 7.886 & 3.679 & 0.265 & 2.144 & 0.036 & \\
\hline 3. TNF- $\alpha$ & 0.715 & 0.306 & 0.289 & 2.338 & 0.023 & \\
\hline \multicolumn{7}{|c|}{ Model 3. Body and object use score as dependent variable } \\
\hline 1. Constant & 0.350 & 4.128 & & 0.085 & 0.933 & 0.119 \\
\hline 2. Gender & 2.542 & 3.101 & 0.101 & 0.820 & 0.416 & \\
\hline 3. $\mathrm{TNF}-\alpha$ & 0.803 & 0.258 & 0.383 & 3.114 & 0.003 & \\
\hline \multicolumn{7}{|c|}{$\begin{array}{l}\text { Model 4. Language and communication score as dependent } \\
\text { variable }\end{array}$} \\
\hline 1. Constant & -2.971 & 3.804 & & -0.781 & 0.438 & 0.153 \\
\hline 2. Gender & 4.463 & 2.858 & 0.188 & 1.562 & 0.124 & \\
\hline 3. $\mathrm{TNF}-\alpha$ & 0.792 & 0.238 & 0.402 & 3.334 & 0.002 & \\
\hline \multicolumn{7}{|c|}{$\begin{array}{l}\text { Model 5. Social and adaptive skills score as dependent } \\
\text { variable }\end{array}$} \\
\hline 1. Constant & -1.668 & 3.118 & & -0.535 & 0.595 & 0.175 \\
\hline 2. Gender & 4.09 & 2.342 & 0.208 & 1.746 & 0.086 & \\
\hline 3. $\mathrm{TNF}-\alpha$ & 0.69 & 0.195 & 0.421 & 3.54 & 0.001 & \\
\hline \multicolumn{7}{|c|}{ Model 6. Total ABC score as dependent variable } \\
\hline 1.Constant & -9.445 & 16.096 & & -0.587 & 0.56 & 0.176 \\
\hline 2.Gender & 23.657 & 12.09 & 0.232 & 1.957 & 0.055 & \\
\hline 3.TNF- $\alpha$ & 3.476 & 1.005 & 0.411 & 3.457 & 0.001 & \\
\hline
\end{tabular}


concentrations were positively correlated with severity of autistic symptoms across both TD and ASD subjects, and preliminary evidence for decreased THRIL mRNA expression suggests that this lincRNA could also be associated with ASD pathogenesis.

Although a recent meta-analysis has reported that mainly IL-1 $\beta$ and IL-6 levels are significantly increased in ASD [14], a number of studies have reported that TNF- $\alpha$ concentrations are also increased in blood, cerebrospinal fluid or post-mortem brain tissue [13-15, 19-23]. Our study has confirmed these latter findings in our cohort of subjects and importantly that blood concentrations of TNF- $\alpha$ are positively associated with ASD symptom severity, thus indicating that TNF- $\alpha$ could be an important cytokine biomarker in ASD. It is still unclear whether the increased levels of TNF- $\alpha$ and other cytokines are a reflection of a pro-inflammatory status in ASD children or dysfunctional immune regulation occurring in autism pathogenesis. However, recent animal model and epidemiological studies have indicated that infection, especially during pregnancy, could be critically involved in the etiology of autism [27-31]. Maternal [17] and neonatal [18] cytokine profiles are also associated with the subsequent development of ASD, suggesting that maternal and/or neonatal infections could contribute as well. Animal studies have additionally shown that immunological challenges with lipopolysaccharide (LPS) or PolyI/C treatment during pregnancy can lead to autismlike symptoms [32-33].

How could a maternal or neonatal infection/immune response lead to brain dysfunction and subsequent ASD symptoms? TNF- $\alpha$ is mainly secreted by macrophages and is broadly involved in the innate immune response through the TNF receptor (TNFR) and activates NF- $\mathrm{bb}$ to regulate down-stream genes. TNF- $\alpha$, as well as IL-1's and IL-6, can all cross from the peripheral blood into the brain to directly affect brain function via their receptors [34]. In humans, preeclampsia and placental ischemia, which are associated with increased incidence of ASD [35], also increase TNF- $\alpha$ concentrations and this in turn can alter the permeability of the blood-brain barrier and influence brain development and function [35]. Similarly, TNF- $\alpha$ can influence the intestinal epithelial barrier and it is possible that elevated concentrations may contribute to gastrointestinal problems that are often associated with ASD [36], although a recent study did not find such an association [13]. Additionally, within the brain itself, microglial cells can secrete TNF- $\alpha[37,38]$ and microglial dysfunction may lead to ASD pathogenesis, although further studies are clearly required to establish whether microglial secreted TNF- $\alpha$ contributes to ASD. Finally, inflammatory cytokines such as TNF- $\alpha$ are important modulators of neurogenesis [39], and altered neocortical neurogenesis has been implicated in ASD [40].

We have provided the first preliminary evidence that expression of the long noncoding RNA, THRIL, is decreased in ASD, although our results need to be confirmed in a larger cohort of subjects. A recent study has shown that increased THRIL expression in macrophages following LPS stimulation may regulate TNF- $\alpha$ expression through an epigenetic mechanism [24]. However, TNF- $\alpha$ can reduce THRIL expression via a negative feedback action [24], and since we found that its expression is decreased in ASD children this might suggest that it is the increased TNF- $\alpha$ which is responsible for. However, while this requires further research, overall our findings

\section{THRIL}

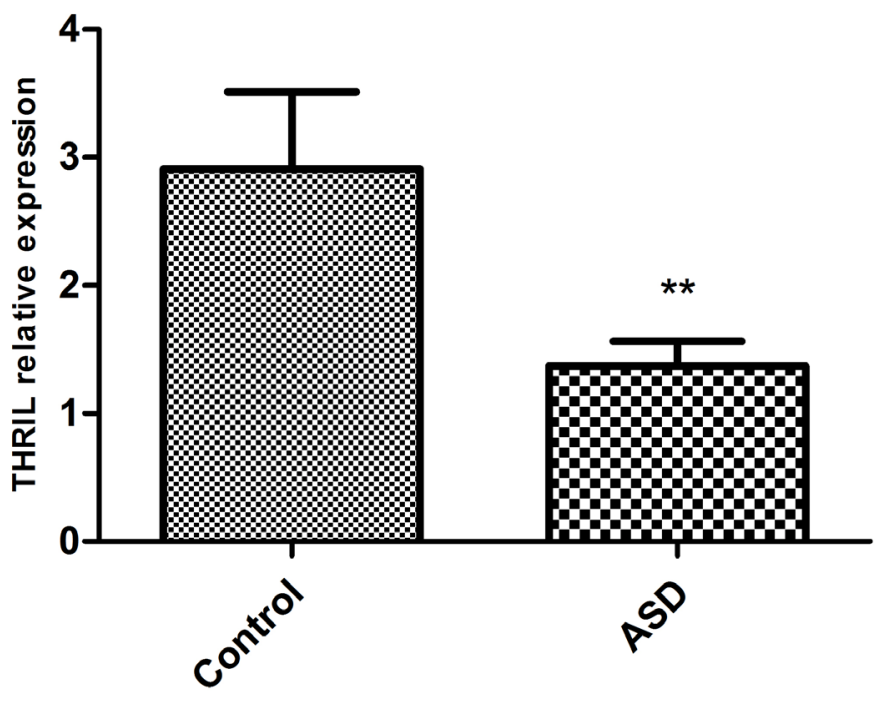

Figure 2: Mean \pm SEM THRIL mRNA expression (arbitrary units) in blood samples taken from ASD (n=10) and TD $(\mathbf{n}=8)$ subjects. $(\mathrm{t}$-test $* * \mathrm{p}<0.01)$. 
generally support an involvement of TNF- $\alpha$ signaling in ASD, although whether via macrophages or microglial cells, or both, remains to be established.

The TNF- $\alpha$ mediated signaling pathway has been extensively studied and several inhibitors or monoclonalantibodies have been successfully used for the treatment of rheumatoid arthritis and inflammatory bowel disease [41, 42]. Although TNF- $\alpha$ has been implicated in several brain disorders, such as Alzheimer's disease [43], it has yet to be explored as a specific neurotherapeutic target in ASD [23, 44, 45]. However, several anti-inflammatory drugs have been shown to have some therapeutic benefit in ASD children [45].

Our study also found evidence for a significant (uncorrected) increase of IL-17A level in ASD children. Th17 related cytokines have also been found to be increased in ASD children by other studies, and a recent study using a mouse model has reported that maternal infection caused Th17 over-activation and autistic-like symptoms, which could be blocked by IL-17 antibody [46]. The clinical significance of Th17-related cytokines in ASD therefore also merits further investigation.

In summary, our study further supports a role for altered TNF- $\alpha$ and its regulation in ASD as the most sensitive cytokine biomarker and for the first time implicate the non-coding LincRNA THRIL which contributes to its regulation. Additionally, $\mathrm{TNF}-\alpha$ and its regulation may hold potential as a future therapeutic target.

\section{MATERIALS AND METHODS}

\section{Subjects}

This study was reviewed and approved by the Human Ethics Committee of the third people's Hospital. The subjects in the autism group $(n=32)$ were recruited from the three training schools for autistic children in Chengdu. After obtaining written informed consent from the children's parents or legal guardians, the children in the autism group were diagnosed in accordance with DSM-IV-TR criteria for ASD. The autism Behavior Checklist (ABC) was also used to confirm the diagnosis of ASD and provide a measure of symptom severity. The subjects in the typically developing (TD) control group $(n=28)$ were recruited from volunteers at a primary school in the same city. The demographic data for the two groups are shown in Table 1.

\section{Autism Behavior Checklist (ABC)}

The autism behavior checklist (ABC) questionnaire was used as an instrument to quantify symptom severity in the ASD group. The ABC consists of 57 items and 5 scales (1) Sensory behavior, (2) Social relating, (3) Body and Object use, (4) Language and communication (5) Social and adaptive skills [25]. Each item is rated on a 4-point scale ranging from 0 to 3 (reflecting the degree of severity) as assessed by a researcher interviewing the child's parents/caregiver. A widely used Chinese translation of the $\mathrm{ABC}$ was used [26] and in the current cohort of subjects showed good internal consistency (Cronbach's $\alpha=0.892$ ).

\section{Blood sampling and measurement of cytokine concentrations}

A fasting blood sample $(5 \mathrm{~mL})$ was drawn from each ASD and TD subject and the blood was centrifuged at $1200 \mathrm{~g}$ for $10 \mathrm{~min}$, within 2 hours. The serum was then aliquoted into $500-\mu \mathrm{L}$ straws and frozen at $-80^{\circ} \mathrm{C}$ until use. Serum concentrations of Th1/Th2 and Th17 related cytokines, were measured by MILLIPLEX MAP custom Human Magnetic Bead Panel Kits (Millipore, Billerica, MA, USA) based on the Luminex xMAP technology. Concentrations of the cytokines $(\mathrm{pg} / \mathrm{ml}$ or $\mathrm{ng} / \mathrm{ml}$ ) were calculated using a standard curve. Two replicate quality control samples were run with each assay (replicate QC1 samples, low level; replicate QC2 samples, high level). The coefficients of variation (CVs) of replicate quality control samples were $<10 \%$ for all cytokines.

\section{Analysis of THRIL mRNA}

Total RNA was extracted from whole blood RNAiso Plus (D9108A; TaKaRa, Dalian, China), and the RNA concentration was measured by ultraviolet spectroscopy (Nanodrop 2000; Thermo, Massachusetts, USA). Total RNA (500 ng) was used for reverse transcription with a PrimeScriptRT reagent kit and gDNA Eraser (DRR047A; TaKaRa). Primers were designed and synthesized by Ribobio (Guangzhou, China); $\beta$-actin was used as an endogenous control for gene expression analysis. The sequences of the PCR primer pairs for each gene are as follows: Forward: 5'-AACTCCTGACCTCAGGTGATCCAT-3'; Reverse:5'-AAGGGAGTTTCAGAAGGTGTGGCT-3'. For quantitative real-time PCR (qRT-PCR), we used a realtime PCR instrument (Thermal Cycler Real Time System, ABI7500) with the SYBRPremix Ex Taq II (DRR820A; TaKaRa). PCR cycling conditions included pre-denaturing at $95^{\circ} \mathrm{C}$ for $10 \mathrm{~min}$, followed by 40 cycles $\left(94^{\circ} \mathrm{C}\right.$ for $15 \mathrm{~s}, 60$ ${ }^{\circ} \mathrm{C}$ for $1 \mathrm{~min}, 72^{\circ} \mathrm{C}$ for $15 \mathrm{~s}$ ) and by an extension at $72^{\circ} \mathrm{C}$ for $30 \mathrm{~s}$. The mean threshold cycle $(\mathrm{Ct})$ values were normalized to $\beta$-actin, and the relative mRNA levels of THRIL were analyzed by the $\Delta \Delta C_{T}$ method. Samples were analyzed in triplicate.

\section{Author contributions}

All of the authors mentioned above participated in this work. The first author and the two corresponding authors carried out the main experimental work and designed the study and wrote the paper. Li Huang took part in the molecular work, Tianying Pan, Xiaohong Li, Hua Li, Huawei Liu and Hua Zhu were involved in the data collection. 


\section{ACKNOWLEDGMENTS}

We thank all the ASD families who support the study. We would also like to thank all the undergraduate volunteers, especially Miss Xiao yue for their help to collect the samples.

\section{CONFLICTS OF INTEREST}

All of the authors declare that they have no conflicts of interests.

\section{FUNDING}

This study was supported by the Science and technology Huimin plan of Chengdu Municipal Science and Technology Bureau (no: 2014-HM01-00232$\mathrm{SF}$ ); Basic research project of Sichuan province (no: 2016JY0185); National Natural Science Foundation (NSFC) grant (no: 31530032).

\section{REFERENCES}

1. Baird G, Simonoff E, Pickles A, Chandler S, Loucas T, Meldrum D, Charman T. Prevalence of disorders of the autism spectrum in a population of children in South Thames: the Special Needs and Autism Project (SNAP). Lancet. 2006; 368:210-5.

2. Chakrabarti S, Fombonne E. Pervasive developmental disorders in preschool children: confirmation of high prevalence. Am J Psychiatry. 2005; 162:1133-41.

3. Zhou WZ, Ye AY, Sun ZK, Tian HH, Pu TZ, Wu YY, Wang DD, Zhao MZ, Lu SJ, Yang CH, Wei L. Statistical analysis of twenty years (1993 to 2012) of data from mainland China's first intervention center for children with autism spectrum disorder. Mol Autism. 2014; 5:52.

4. Baxter AJ, Brugha TS, Erskine HE, Scheurer RW, Vos T, Scott JG. The epidemiology and global burden of autism spectrum disorders. Psychol Med. 2015; 45:601-13.

5. Careaga M, Ashwood P. Autism spectrum disorders: from immunity to behavior. Methods Mol Biol. 2012; 934:219-40.

6. Kidd PM. Autism, an extreme challenge to integrative medicine. Part: 1: The knowledge base. Altern Med Rev. 2002; 7:292-316.

7. Lai MC, Lombardo MV, Baron-Cohen S. Autism. Lancet. 2014; 383:896-910.

8. Bailey A, Le Couteur A, Gottesman I, Bolton P, Simonoff E, Yuzda E, Rutter M. Autism as a strongly genetic disorder: evidence from a British twin study. Psychol Med. 1995; 25:63-77.

9. Cohly HH, Panja A. Immunological findings in autism. Int Rev Neurobiol. 2005; 71:317-41.
10. Jyonouchi H, Sun S, Itokazu N. Innate immunity associated with inflammatory responses and cytokine production against common dietary proteins in patients with autism spectrum disorder. Neuropsychobiology. 2002; 46:76-84.

11. Jyonouchi H, Geng L, Ruby A, Zimmerman-Bier B. Dysregulated innate immune responses in young children with autism spectrum disorders: their relationship to gastrointestinal symptoms and dietary intervention. Neuropsychobiology. 2005; 51:77-85.

12. Wong PH, White KM. Impact of immunoglobulin therapy in pediatric disease: a review of immune mechanisms. Clin Rev Allergy Immunol. 2016; 51:303-14.

13. Ferguson BJ, Marler S, Altstein LL, Lee EB, Mazurek MO, McLaughlin A, Macklin EA, McDonnell E, Davis DJ, Belenchia AM, Gillespie CH, Peterson CA, Bauman $\mathrm{ML}$, et al. Associations between cytokines, endocrine stress response, and gastrointestinal symptoms in autism spectrum disorder. Brain Behav Immun. 2016; 58:57-62.

14. Masi A, Quintana DS, Glozier N, Lloyd AR, Hickie IB, Guastella AJ. Cytokine aberrations in autism spectrum disorder: a systematic review and meta-analysis. Mol Psychiatry. 2015; 20:440-6.

15. Yang CJ, Tan HP, Yang FY, Liu CL, Sang B, Zhu XM, Du YJ. The roles of cortisol and pro-inflammatory cytokines in assisting the diagnosis of autism spectrum disorder. Res Autism Spectr Disord. 2015; 9:174-81.

16. Abdallah MW, Larsen N, Grove J, Nørgaard-Pedersen B, Thorsen P, Mortensen EL, Hougaard DM. Amniotic fluid inflammatory cytokines: potential markers of immunologic dysfunction in autism spectrum disorders. World J Biol Psychiatry. 2013; 14:528-38.

17. Jones KL, Croen LA, Yoshida CK, Heuer L, Hansen R, Zerbo O, DeLorenze GN, Kharrazi M, Yolken R, Ashwood $\mathrm{P}$, Van de Water J. Autism with intellectual disability is associated with increased levels of maternal cytokines and chemokines during gestation. Mol Psychiatry. 2017; 22:273-9.

18. Krakowiak P, Goines PE, Tancredi DJ, Ashwood P, Hansen RL, Hertz-Picciotto I, Van de Water J. Neonatal cytokine profiles associated with autism spectrum disorder. Biol Psychiatry. 2017; 81:442-51.

19. Lee RH, Mills EA, Schwartz N, Bell MR, Deeg KE, Ruthazer ES, Marsh-Armstrong N, Aizenman CD. Neurodevelopmental effects of chronic exposure to elevated levels of pro-inflammatory cytokines in a developing visual system. Neural Dev. 2010; 5:2.

20. Li X, Chauhan A, Sheikh AM, Patil S, Chauhan V, Li XM, Ji L, Brown T, Malik M. Elevated immune response in the brain of autistic patients. J Neuroimmunol. 2009; 207:111-6.

21. Malik M, Sheikh AM, Wen G, Spivack W, Brown WT, Li X. Expression of inflammatory cytokines, Bcl2 and cathepsin D are altered in lymphoblasts of autistic subjects. Immunobiology. 2011; 216:80-5. 
22. Vargas DL, Nascimbene C, Krishnan C, Zimmerman AW, Pardo CA. Neuroglial activation and neuroinflammation in the brain of patients with autism. Ann Neurol. 2005; 57:67-81.

23. Xu N, Li X, Zhong Y. Inflammatory cytokines: potential biomarkers of immunologic dysfunction in autism spectrum disorders. Mediators Inflamm. 2015; 2015:531518.

24. Li Z, Chao TC, Chang KY, Lin N, Patil VS, Shimizu C, Head SR, Burns JC, Rana TM. The long noncoding RNA THRIL regulates TNF $\alpha$ expression through its interaction with hnRNPL. Proc Natl Acad Sci U S A. 2014; 111:1002-7.

25. Goldstein S, Naglieri JA. Encyclopedia of Child Behavior and Development. Springer US. 2011, 10-11.

26. Shen Y, Ou J, Liu M, Shi L, Li Y, Xiao L, Dong H, Zhang F, Xia K, Zhao J. Altered plasma levels of chemokines in autism and their association with social behaviors. Psychiatry Res. 2016; 244:300-5.

27. Arrode-Brusés G, Brusés JL. Maternal immune activation by poly I:C induces expression of cytokines IL- $1 \beta$ and IL-13, chemokine MCP-1 and colony stimulating factor VEGF in fetal mouse brain. J Neuroinflammation. 2012; 9:83.

28. Brown AS. Epidemiologic studies of exposure to prenatal infection and risk of schizophrenia and autism. Dev Neurobiol. 2012; 72:1272-6.

29. Parker-Athill EC, Tan J. Maternal immune activation and autism spectrum disorder: interleukin-6 signaling as a key mechanistic pathway. Neurosignals. 2010; 18:113-28.

30. Smith SE, Li J, Garbett K, Mirnics K, Patterson PH. Maternal immune activation alters fetal brain development through interleukin-6. J Neurosci. 2007; 27:10695-702.

31. Ziats MN, Rennert OM. Expression profiling of autism candidate genes during human brain development implicates central immune signaling pathways. PLoS One. 2011; 6:e24691.

32. Bauman MD, Iosif AM, Smith SE, Bregere C, Amaral DG, Patterson PH. Activation of the maternal immune system during pregnancy alters behavioral development of rhesus monkey offspring. Biol Psychiatry. 2014; 75:332-41.

33. Forrest CM, Khalil OS, Pisar M, Smith RA, Darlington LG, Stone TW. Prenatal activation of Toll-like receptors-3 by administration of the viral mimetic poly(I:C) changes synaptic proteins, N-methyl-D-aspartate receptors and neurogenesis markers in offspring. Mol Brain. 2012; 5:22.

34. Banks WA. The blood-brain barrier in neuroimmunology: tales of separation and assimilation. Brain Behav Immun. $2015 ; 44: 1-8$.
35. Walker CK, Krakowiak P, Baker A, Hansen RL, Ozonoff S, Hertz-Picciotto I. Preeclampsia, placental insufficiency, and autism spectrum disorder or developmental delay. JAMA Pediatr. 2015; 169:154-62.

36. Gorrindo P, Williams KC, Lee EB, Walker LS, McGrew SG, Levitt P. Gastrointestinal dysfunction in autism: parental report, clinical evaluation, and associated factors. Autism Res. 2012; 5:101-8.

37. Pate AB, Tsilioni I, Leeman SE, Theoharides TC. Neurotensin stimulates sortilin and mTOR in human microglia inhibitable by methoxyluteolin, a potential therapeutic target for autism. Proc Natl Acad Sci U S A. 2016; 113:7049-58.

38. Zhang B, Zou J, Han L, Rensing N, Wong M. Microglial activation during epileptogenesis in a mouse model of tuberous sclerosis complex. Epilepsia. 2016; 57:1317-25.

39. Borsini A, Zunszain PA, Thuret S, Pariante CM. The role of inflammatory cytokines as key modulators of neurogenesis. Trends Neurosci. 2015; 38:145-57.

40. Packer A. Neocortical neurogenesis and the etiology of autism spectrum disorder. Neurosci Biobehav Rev. 2016; 64:185-95.

41. Felice C, Marzo M, Pugliese D, Papa A, Rapaccini GL, Guidi L, Armuzzi A. Therapeutic drug monitoring of antiTNF- $\alpha$ agents in inflammatory bowel diseases. Expert Opin Biol Ther. 2015; 15:1107-17.

42. Oda K, Minata M. Drug free remission after steroiddependent disappearance of lymphoproliferative disorder in rheumatoid arthritis patient treated with TNF- $\alpha$ blockade: case study. Springer plus. 2015; 4:1-5.

43. Cheng X, Shen Y, Li R. Targeting TNF: a therapeutic strategy for Alzheimer's disease. Drug Discov Today. 2014; 19:1822-7.

44. Burton A, Kizhner O, Brown MB, Peltier MR. Effect of experimental genital mycoplasmosis on gene expression in the fetal brain. J Reprod Immunol. 2015; 93:9-16.

45. Di Marco B, Bonaccorso CM, Aloisi E, D'Antoni S, Catania MV. Neuro-inflammatory mechanisms in developmental disorders associated with intellectual disability and autism spectrum disorder: a neuro-immune perspective. CNS Neurol Disord Drug Targets. 2016; 15:448-63.

46. Choi GB, Yim YS, Wong H, Kim S, Kim H, Kim SV, Hoeffer CA, Littman DR, Huh JR. The maternal interleukin17a pathway in mice promotes autism-like phenotypes in offspring. Science. 2016; 351:933-9. 